\title{
The llizarov technology for closed reduction of hip dislocation in children with developmental hip dysplasia
}

\author{
M.P. Teplenky, E.V. Oleinikov, V.S. Bunov
}

Ilizarov National Medical Research Centre for Traumatology and Orthopedics, Kurgan, Russian Federation

\begin{abstract}
Introduction The possibility of gradual closed reduction of hip dislocation in children over 1.5 years old is considered doubtful. Purpose Analysis of long-term results of applying the Ilizarov technique of gradual closed reduction in combination with the reconstruction of the hip joint components. Methods The outcomes of treatment of 62 children (81 joints) with congenital hip dislocation in the follow-up period from 5 to 16 years were studied. The treatment method included closed reduction of the dislocation using the technology proposed by G.A. Ilizarov and subsequent reconstruction of the joint components. The patients are divided into two groups based on their age. The first group included 33 patients (43 joints) under the age of 5 years. The second group consisted of 29 patients (38 joints) aged 5-8 years. Results Closed reduction failed in five cases. The recurrence of dislocation after closed reduction was $5.3 \%$. The rate of aseptic necrosis after closed reduction was $9.7 \%$. Good functional outcomes were reported in $87.7 \%$. They were significantly better in the younger group. The proportion of good anatomical results did not depend on age and was $77 \%$ in general. Poor results were obtained in $8.8 \%$. Conclusion The anatomical and functional outcomes and the number of complications by using the technique described were comparable to other methods of gradual closed reduction of hip dislocation. But the technique we have described expands the age restrictions for its use.

Keywords: closed reduction, skeletal traction, Ilizarov technique, innominate osteotomy, femoral derotation osteotomy
\end{abstract}

\section{INTRODUCTION}

Developmental dysplasia of the hip has been recognized as one of the most common orthopedic pathologies in children. Despite the development of methods for its early diagnosis and functional treatment, there are still patients over 1.5 years old who need complex and aggressive orthopedic treatment. Recommendations for their treatment remain controversial and vary from conservative therapy in the age of up to 3 years to reconstructive intervention at 1.5 years [1]. One of the controversial issues is the method of reduction [2]. Supporters of closed reduction point to the risk of contracture and possible early progression of coxarthrosis. Orthopedic surgeons who prefer open reduction observe high incidence of complications such as reluxation and aseptic necrosis, and the need for additional reconstructive interventions on the joint components. However, it should be noted that the capability of post-reduction development of the joint at this age fade away regardless of the reduction method used [3]. Therefore, the Petit-Morel technique that implies a gradual closed reduction of the dislocation followed by the osteotomy of the ilium seems to be preferable [4]. However, its application is limited by five years of age. The author himself points to lower efficiency of the technology after 3 years of age [2].

G.A. Ilizarov proposed a method for gradual closed reduction of hip dislocation using an external fixation device in 1988. It was originally intended to treat school-age children. Later, as the methods of transosseous elements insertion into the pelvic bone had improved, the age limits for the application of the technique were expanded. Currently, the Ilizarov technology has been used as the first stage of surgical treatment of congenital hip dislocation in children from the age of two years [5].

The purpose of the study was to evaluate the long-term results of the application of the Ilizarov method in combination with the reconstruction of joint components.

\section{MATERIAL AND METHODS}

We studied treatment outcomes of 62 children (81 joints) with congenital hip dislocation that underwent surgical reconstruction at the Ilizarov Center from 2000 through 2015.

There were 49 girls and 13 boys (ratio, 3.7:1). The youngest age in this series was 1 year 10 months and the maximum age was 8 years (average age, 5.2 years).

Inclusion criteria into the study:

1) congenital hip dislocation of grades III-IV (Tonnis scale) [6];

2) follow-up period not less than 5 years; 
3) application of the technology involving reduction of dislocation with the external frame and reconstruction of joint components.

\section{Exclusion criteria:}

1) developmental dysplasia of the hip in grade I-II (Tonnis scale) [6];

2) developmental dysplasia of the hip, complicated by aseptic necrosis;

3) joint disorders characteristic for arthrogryposis and neurogenic pathology.

Mean follow up was 8.3 years (range, 5-17 years). McKey criteria were used to assess the functional outcomes [7]. Anatomical results were studied by pelvic radiography.

The following radiometric parameters were measured:

1) acetabular index (AI) (in closure of Y-shaped joints with the angle of weight-bearing surface (WBS);

2) Idelberger-Frank angle (IFA) $\left(\mathrm{N}=46-50^{\circ}\right)$ [12];

3) proximal displacement index of the femoral head (PDI) - the grade of Shenton line disruption in $\mathrm{mm}$;

4) acetabulum-head index (AHI) - ratio of the distance from the medial rim of the head to Ombredann line relative to the distance from the medial to the lateral rim of the head which normal value should be $0.85-1.0$;

5) center-edge angle of Wiberg (CEA).

The relations in the joints were evaluated in the radiographs after frame removal and at long-term follow-ups.
Severin criteria were used for evaluating radiographic findings. Degenerative changes in the femoral head were rated with Tonnis classification [6].

The study was performed in accordance with the ethics standards of the Helsinki declaration of the World Health Organization and national guidelines. Legal representatives gave their informed consents to include their children in the study.

Microsoft Excel 2010 was used for statistical processing. Quantitate findings were non-weighed variation rows, means and their deviations and significance of difference with Wilcoxon T-test for related samples.

The surgical technology included closed reduction of hip dislocation according to G.A. Ilizarov and further reconstruction of the joint components [8]. Closed reduction of dislocation implied gradual bringing of the femur down till the lower edge of the acetabulum, transfer of the head on the reduction axis followed by gradual transport of the head into the acetabulum [5]. Re-orientation osteotomy of the ilium was used for correction of the acetabular dysplasia which was supplemented by incomplete periacetabular osteotomy in 10 cases. Intertrochanteric corrective osteotomy was performed for reconstruction of the femur.

The joints were fixed with a removable plaster brace upon frame dismantling. Rehabilitation measures were indicated for $8-10$ months. Full weight-bearing was allowed after that period.

\section{RESULTS}

It is known that in the age from 1.5 to 4 years (the so-called "golden period") the development of the acetabulum after its reorientation and reconstructive interventions may continue, thus increasing the chances of achieving a favorable outcome [9-11]. Taking this fact into account, our patients were divided into two groups. The first group included 33 children (43 joints) who were under five years old at the start of treatment. The second group was 29 children (38 joints) aged 5-8 years.

Distribution of joints by severity of dislocation (Tonnis scale) in group 1: grade III (PDI, 25-35 mm) were 25 joints, grade IV (PDI $>35 \mathrm{~mm}$ ) were 18 joints; in the second group: grade III were 22 joints, grade IV were 16 joints. In four patients with bilateral lesions in group 1 and in five patients in group 2, dislocations were asymmetric.

In two cases from group 1 and in three patients from group 2, proximal displacement occurred when the head was moved to the axis of reduction, which was regarded as a soft tissue blockade of the joint. In those cases, an open reduction was performed in combination with a corrective shortening osteotomy of the femur. During the first three months after the removal of the apparatus, two patients with unilateral dislocation and one with bilateral lesion (1 joint in group 1,2 joints in group 2) had a relapse of dislocation. In all those cases, an open reduction of the dislocation was performed with a shortening osteotomy of the femur. Eight patients who underwent open reduction were assigned to a separate group (group 3).

At removing the apparatus, in most cases, structural abnormalities in the head were noted such as areas of cystic restructuring. Within the following 8 to 12 months, regression of these changes was noted in most cases. Such disorders were regarded as a process of post-reduction adaptation of the joint elements. After closed reduction, dystrophic changes were defined as aseptic necrosis in three joints in patients of group 2 (grades III and IV) and in two patients of the first group (grade III). In one case of grade IV, femoral head necrosis developed after open reduction. In two cases, subcapital valgus developed due to dystrophic changes.

According to X-ray findings upon removing the apparatus, the indicators characterizing the condition of the cavity and joint relations improved in both 
groups. In patients of the first group, a significant improvement in the X-ray parameters of the slope of the arch and the spherical cavity was revealed in the process of further observation, which indirectly confirms that its development continued. In the second group, the indicators did not change significantly and corresponded to the normal border. The degree of lateral inclination of the cavity was greater in the children of the first group, but the difference was not statistically significant. In both groups, after removing the apparatus, the reverse disruption of the Shenton line was noted, more pronounced in young children. Those changes were regarded as a persistent interposition of soft tissues between the head and the cavity slope. The subsequent decrease in the degree of the Shenton line disruption might be associated with a gradual penetration of the head. A statistically significant change in the indices of head centering in the cavity was observed only in patients of the first group (Table 1).

Patients in group 3 had a more significant increase in the indices of head centering and Shenton line restoration after frame removal. Changes in the acetabular parameters did not have significant difference from the first group children.

\section{Treatment outcomes in group 1}

Radiographic results were analyzed in 31 children of the first group. IA type - 10 joints, IIA type 19 joints, IIB type -4 joints, type III -5 joints, type IV - 1 joint, type $\mathrm{V}-1$ joint. Radiographic results of nine patients with bilateral dislocation were: IA type -4 joints, IIA type -8 joints, IIB types 2 joints, III type -4 joints. Radiographic results of 22 patients with unilateral hip dislocation: IA type6 joints, IIA type -11 joints, IIB type -2 joints, III type -1 joint, IV type -1 joint, $V$ type -1 joint.

Clinical results were analyzed in 30 children of the first group (not including a patient with reluxation): I class - 16, II class - 12, III class - 2. Results of 9 patients with bilateral dislocation: I class -5 ,
II class -4 . Results of 21 patients with unilateral hip dislocation: I class -11 , II class -8 , III class -2 .

Treatment outcomes in group 2

Radiographic results were analyzed in 26 patients of group 2: IA type -6 joints, IIA type -18 joints, IIB type -4 joints, III type -3 joints, IV type -1 joint, $\mathrm{V}$ type -2 joints. Radiographic results of 10 patients with bilateral dislocation: IA type - 3 joints, IIA type 9 joints, IIB type -3 joints, III type -2 joints, V type - 1 joint. Radiographic results of 16 patients with unilateral hip dislocation: IA type -3 joints, IIA type 9 joints, IIB type -1 joint, III type -1 joint, IV type -1 joint, $\mathrm{V}$ type -1 joint.

Clinical outcomes were analyzed in 24 patients (not including 2 patients with reluxation): I class 12 joints, II class -10 , III class -2 . Results of 7 patients with bilateral hip dislocation: I class -3 , II class -4 . Results of 17 patients with unilateral dislocation: I class -9 , II class -6 , III class -2 .

Clinical results in group 3: IIa class - 6 joints, III class - 2 joints. Radiographic results in group 3: IIA type -4 joints, IIB type -2 joints, III type -2 joints.

\section{Case 1}

Patient S, 4 years old, bilateral congenital dislocation of the hips (Fig. 1)

The child underwent surgery on both components of the hip joints using external fixation devices (Fig. 2).

At the follow-up 12 years later, the relations in the hip joints were preserved, the femoral heads were centered in the cavities, and the coverage of the femoral heads was satisfactory (Fig. 3).

\section{Case 2}

Patient K, 5 years old, bilateral congenital dislocation of the hips (Fig. 4)

The patient underwent staged reconstruction of the pelvis and femurs on both sides using the Ilizarov apparatus (Fig. 5).

At 17-year follow-up, the condition of the joints was satisfactory. The femoral heads are spherical, the articular surfaces are congruent (Fig. 6).

Table 1

Dynamics of radiometric parameters in the joints after closed reduction of hip dislocation (groups 1 and 2) and open reduction (group 3)

\begin{tabular}{|c|l|c|c|c|c|c|}
\hline \multirow{2}{*}{ Group } & \multirow{2}{*}{ Period of study } & \multicolumn{5}{|c|}{ Radiometric parameters } \\
\cline { 3 - 7 } & & AI (WBS) $\left(^{\circ}\right)$ & IFA $\left(^{\circ}\right)$ & PDI $(\mathrm{mm})$ & CEA $\left(^{\circ}\right)$ & AHI \\
\hline \multirow{3}{*}{$\mathrm{I}(\mathrm{n}=40)$} & Before surgery & $42 \pm 0.7$ & $67 \pm 1.3$ & $47 \pm 3.1$ & & \\
\cline { 2 - 7 } & After frame removal & $13 \pm 0.4^{*}$ & $56 \pm 1.7^{*}$ & $-17 \pm 1.5^{*}$ & $24.6 \pm 0.8$ & $0.84 \pm 0.02$ \\
\cline { 2 - 7 } & Long-term follow-up & $39 \pm 0.5$ & $68 \pm 0.9$ & $40 \pm 2.5$ & & \\
\hline \multirow{3}{*}{$2(\mathrm{n}=33)$} & Before surgery & $40 \pm 0.3$ & $69 \pm 0.5$ & $52.5 \pm 3.5$ & & \\
\cline { 2 - 7 } & After frame removal & $14 \pm 0.3^{*}$ & $57 \pm 0.5^{*}$ & $-10 \pm 0.7^{*}$ & $23.6 \pm 0.6$ & $0.85 \pm 0.05$ \\
\cline { 2 - 7 } & Long-term follow-up & $11.9 \pm 0.3^{* *}$ & $54 \pm 0.4$ & $2 \pm 0.07^{* *}$ & $25 \pm 1.4$ & $0.83 \pm 0.04$ \\
\hline \multirow{3}{*}{$3(\mathrm{n}=8)$} & Before surgery & $39 \pm 0.5$ & $68 \pm 0.9$ & $40 \pm 2.5$ & & \\
\cline { 2 - 7 } & After frame removal & $12 \pm 0.4^{*}$ & $54 \pm 1.2^{*}$ & $0 \pm 0.2^{*}$ & $28 \pm 0.8$ & $0.96 \pm 0.08$ \\
\cline { 2 - 7 } & Long-term follow-up & $9 \pm 0.9^{* *}$ & $52 \pm 0.7$ & $0.3 \pm 0.1$ & $25 \pm 1.0$ & $0.85 \pm 0.07^{* *}$ \\
\hline
\end{tabular}




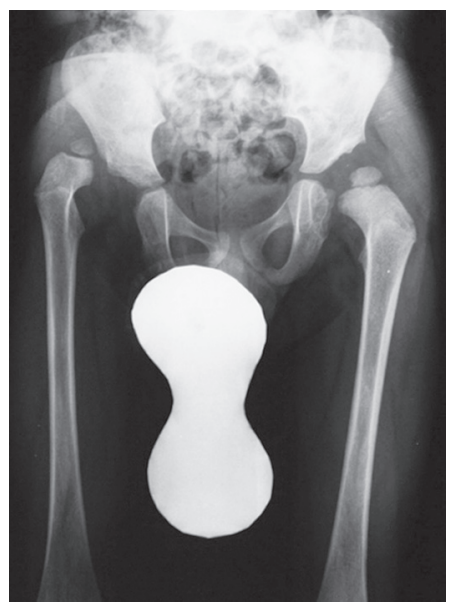

Fig. 1 AP radiograph of the pelvis of patient $\mathrm{S}$ before treatment

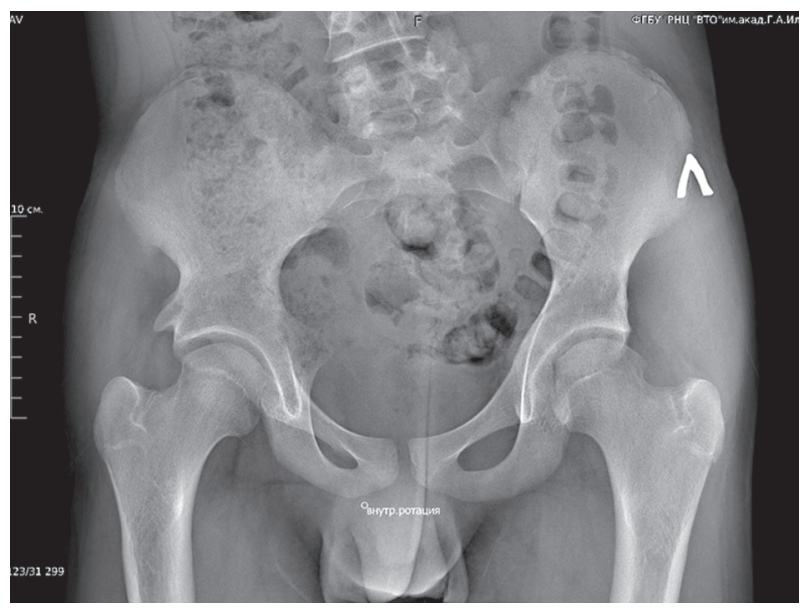

Fig. 3 AP radiograph of the pelvis of patient $S$ at a 12 year follow-up

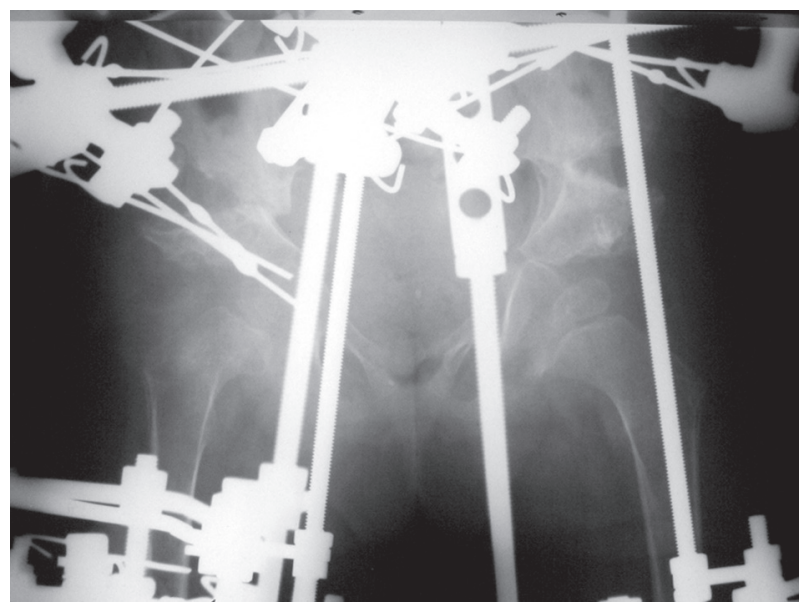

Fig. 5 AP radiograph of the pelvis of patient $\mathrm{K}$ in the course of staged treatment

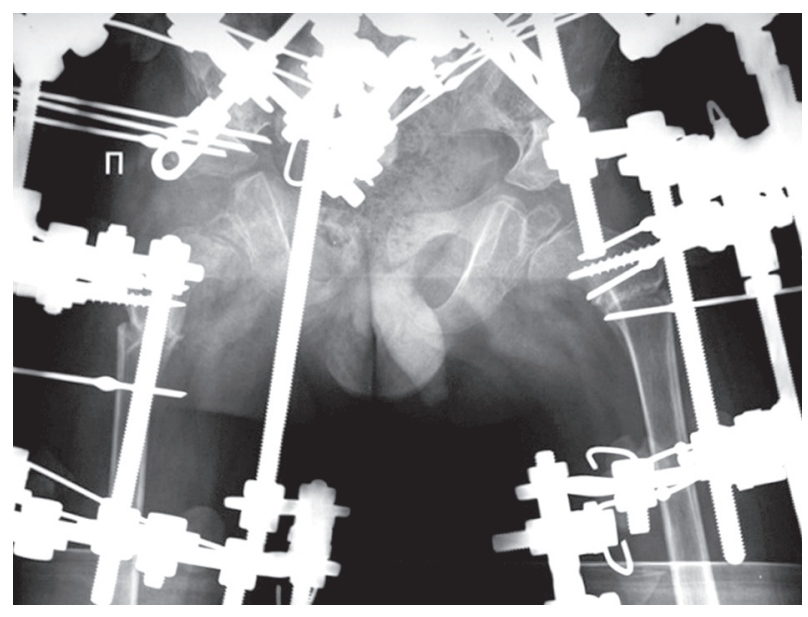

Fig. 2 AP radiograph of the pelvis of patient $S$ in the course of treatment

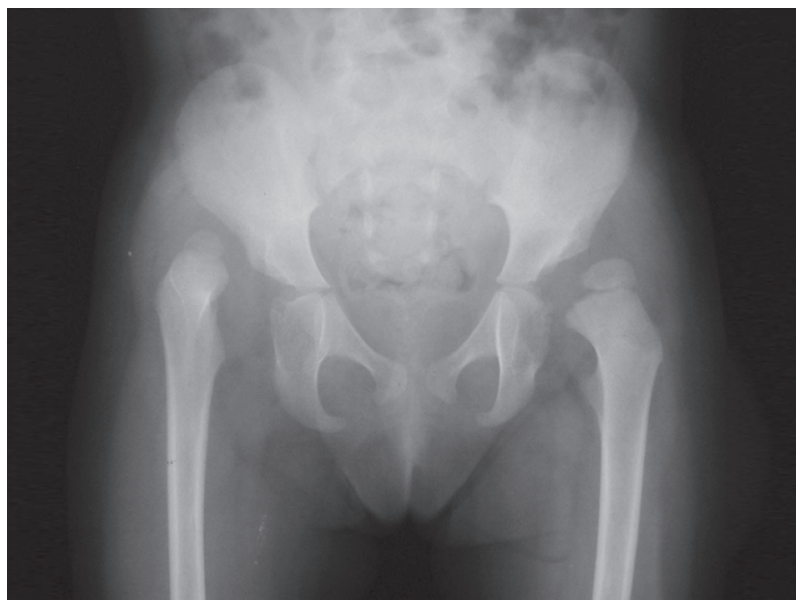

Fig. 4 AP radiograph of the pelvis of patient $\mathrm{K}$ before treatment

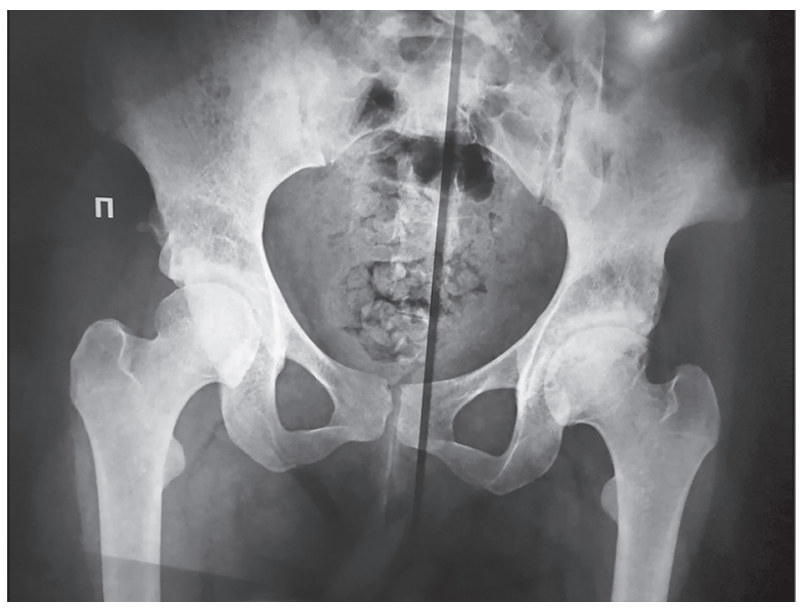

Fig. 6 AP radiograph of the pelvis of patient $\mathrm{K}$ at a 17year follow-up

\section{DISCUSSION}

The goal of treating children with congenital hip dislocation is to sparingly restore the relations in the joint, ensure the development of joint relations, and prevent the development of dystrophic complications. With age, treatment measures become more complicated, and the prognosis becomes less predictable [3]. One of the debatable issues is the method of dislocation reduction. Most authors recognize open reduction as the "gold standard" [12]. The optimal age to use it for neglected dislocation varies from 12 to 18 months [13]. However, according to the literature, the analysis of long-term results of gradual closed reduction technologies shows their advantage in terms of joint survival and arthrosis 
progression in comparison with open reduction methods [2, 14-17].

Methods of gradual closed reduction in older children, including the Petit-Morel technique, involve horizontal skeletal traction. The descent level is determined by the Hilgenreiner line. Next, the hip is abducted and the femoral head is moved towards the Y-shaped cartilage (reduction axis). Penetration of the head into the cavity occurs in a plaster cast for 2-3 months. Then osteotomy of the ilium is performed $[2,3]$. Age restrictions are due to the impossibility of overcoming the tension of the femoral muscles and ligamentous apparatus by applying skeletal traction. The Ilizarov technology assumes the preservation of patient's motor activity. So, the magnitude of possible abduction does not exceed $40^{\circ}$. Therefore, the level of head descending changes to the lower edge of the cavity. Accordingly, the direction of the reduction axis changes from horizontal to oblique-vertical. Prior to the osteotomy of the ilium, only partial immersion of the head into the cavity is produced within 7-10 days. The use of the known technique of cavity transposition excludes the lateroposition of the head by corrective turning of the fragments. The final penetration is achieved during the rehabilitation period after the removal of the apparatus $[5,8]$.

The rate of recurrent dislocations after closed reduction was $5.3 \%$, which is comparable to the data of Rampal et al. (4.3\%), Morel (9.7\%), Morin et al., and with the rates of open reduction (3-15\%) [15, 18-22].

Aseptic necrosis of the femoral head not only impairs the stability of the joint, but also worsens the prognosis in terms of coxarthrosis. Its rates vary from $2-5 \%[2,3,15,23]$ to $60-70 \%$ after closed reduction $[16,24]$. By open reduction, the data are also rather heterogeneous, from $2-5.5 \%[25,26]$ to $50-88 \%$ [ 16 , $20,21,27]$. This is due to certain subjectivity and the use of various criteria in assessing the condition of the joint. In the group of patients presented by us treated by closed reduction of dislocation, the rate of dystrophic complications was $9.7 \%$. It exceeds the findings of C. Morin et al., P. Wicart et al., as well as our previous results $[2,3,8]$. Perhaps one of the reasons is an older average age of the patients.

Good anatomical results were achieved in $77 \%$ of our patients and $8.8 \%$ were poor. According to the literature, good outcomes were reported in 80-93\% of cases after closed reduction and reconstruction of the pelvic component $[4,18,15]$. They were from 73 to $96 \%$ when open reduction was combined with osteotomy of the ilium and femur [25, 27, 28, 29]. However, it should be noted a relatively low (up to 3 years) average age of patients in the groups that showed good outcomes of more than $85 \%$ [4, 18, 25, 27]. A number of authors indicate a significant worsening of patients' outcomes after three years of age $[2,3]$.

Good functional outcomes were observed in $87.7 \%$. They were significantly better in the younger group.

The anatomical results of patients after open reduction did not differ significantly (75\%) from the results of the main group. The functional results were worse. The rate of dystrophic complications was $12.5 \%$. However, taking into account the conditions for performing open reduction and a limited number of cases, the comparison cannot be considered correct.

A number of authors attribute the bilateral lesion to risk factors that aggravate the prognosis [25, 30]. In the analyzed group, we found no differences in the results of treatment of patients with unilateral and bilateral hip dislocation.

Unlike the Petit-Morel technique, the Ilizarov technique has no age restrictions and can be used even in school-age children [31]. The limitations are due to the anatomical features of the joint. The technique is contraindicated in the presence of degenerative changes in the joint, as well as in the case of anterior dislocation of the femoral head [32]. The main factor that may restrict its use is insufficient experience of surgeons with external fixation devices.

\section{CONCLUSIONS}

Anatomical and functional outcomes and the number of complications by using the technique described were comparable with other methods of gradual closed reduction of hip dislocation. At the same time, the technique described by us expands the age limit for its use.

\section{REFERENCES}

1. Ganger R., Radler C., Petje G., Manner H.M., Kriegs-Au G., Grill F. Treatment options for developmental dislocation of the hip after walking age. J. Pediatr. Orthop. B, 2005, vol. 14, no. 3, pp. 139-150. DOI: 10.1097/01202412-200505000-00001

2. Morin C., Bisogno J., Kulkarni S., Morel G. Treatment of late-presenting developmental dislocation of the hip by progressive orthopedic reduction and innominate osteotomy. Our results with more than 30 years of follow up. J. Child. Orthop., 2011, vol. 5, no. 4, pp. 251-260. DOI 10.1007/ s11832-011-0346-2

3. Wicart P., Seringe R., Glorion C., Brassac A., Rampal V. Closed reduction in late-detected developmental dysplasia of the hip: indications, results and complications. J. Child. Orthop., 2018, vol. 12, no. 4, pp. 317-322. DOI 10.1302/1863- 2548.12.180088

4. Morel G. The treatment of congenital dislocation and subluxation of the hip in the older child. Acta Orthop. Scand., 1975, vol. 46, no. 3, pp. 364-399.

5. Shevtsov V.I., Makushin V.D., Teplenky M.P., Atmansky I.A. Lechenie vrozhdennogo vyvikha bedra. Novye tekhnologii osteosinteza moduliami apparata Ilizarova [Treatment of congenital dislocation of the hip. New osteosynthesis technologies with the Ilizarov fixator modules]. Kurgan, Zaurale, 2006, 1000 p. (in Russian)

6. Tönnis D. Surgical treatment of congenital dislocation of the hip. Clin. Orthop. Relat. Res., 1990, no. 258, pp. 33-40. 
7. McKay D.W. A comparison of the innominate and the pericapsular osteotomy in the treatment of congenital dislocation of the hip. Clin. Orthop. Relat. Res., 1974, no. 98, pp. 124-132. DOI: 10.1097/00003086-197401000-00013

8. Teplenky M.P., Makushin V.D., Chirkova N.G. Zakrytoe vpravlenie vyvikha bedra apparatom Ilizarova u detei doshkolnogo vozrasta [Closed reposition of the hip dislocation using the Ilizarov fixator in children of pre-school age]. Genij Ortopedii, 2011, no. 2, pp. 65-69. (in Russian)

9. Ezirmik N., Yildiz K. Advantages of single-stage surgical treatment with Salter innominate osteotomy and Pemberton pericapsular osteotomy for developmental dysplasia of both hips. J. Int. Med. Res., 2012, vol. 40, no. 2, pp. 748-755. DOI: 10.1177/147323001204000240

10. Guarniero R. Dysplasia of hip development: Update. Rev. Bras. Ortop., 2015, vol. 45, no. 2, pp. 116-121. DOI: 10.1016/S2255-4971(15)30279-2

11. Danielsson L. Late-diagnosed DDH: a prospective 11-year follow-up of 71 consecutive patients (75 hips). Acta Orthop. Scand., 2000, vol. 71, no. 3 , pp. 232-242. DOI: $10.1080 / 000164700317411816$

12. Salter R.B., Dubos J.P. The first fifteen year's personal experience with innominate osteotomy in the treatment of congenital dislocation and subluxation of the hip. Clin. Orthop. Relat. Res., 1974, no. 98, pp. 72-103. DOI: 10.1097/00003086-197401000-00009

13. Weinstein S.L., Dolan L.A. Proximal femoral growth disturbance in developmental dysplasia of the hip: what do we know? J. Child. Orthop., 2018, vol. 12, no. 4, pp. 331-341. DOI: 10.1302/1863-2548.12.180070

14. Thomas S.R., Wedge J.H., Salter R.B. Outcome at forty-five years after open reduction and innominate osteotomy for late-presenting developmental dislocation of the hip. J. Bone Joint Surg. Am., 2007, vol. 89, no. 11, pp. 2341-2350. DOI: 10.2106/JBJS.F.00857

15. Rampal V., Sabourin M., Erdeneshoo E., Koureas G., Seringe R., Wicart P. Closed reduction with traction for developmental dysplasia of the hip in children aged between one and five years. J. Bone Joint Surg. Br., 2008, vol. 90, no. 7, pp. 858-863. DOI: 10.1302/0301-620X.90B7.20041

16. Angliss R., Fujii G., Pickvance E., Wainwright A.M., Benson M.K. Surgical treatment of late developmental displacement of the hip. Results after 33 years. J. Bone Joint Surg. Br., 2005, vol. 87, no. 3, pp. 384-394. DOI: 10.1302/0301-620x.87b3.15247

17. Terjesen T., Horn J., Gunderson R.B. Fifty-year follow-up of late-detected hip dislocation: clinical and radiographic outcomes for seventy-one patients treated with traction to obtain gradual closed reduction. J. Bone Joint Surg Am., 2014, vol. 96, no. 4, pp. e28. DOI: 10.2106/JBJS.M.00397

18. Morin C., Rabay G., Morel G. Retrospective review at skeletal maturity of the factors affecting the efficacy of Salter's innominate osteotomy in congenital dislocated, subluxed, and dysplastic hips. J. Pediatr. Orthop., 1998, vol. 18, no. 2, pp. 246-253.

19. Kershaw C.J., Ware H.E., Pattinson R., Fixsen J.A. Revision of failed open reduction of congenital dislocation of the hip. J. Bone Joint Surg. Br., 1993, vol. 75, no. 5, pp. 744-749. DOI: 10.1302/0301-620X.75B5.8376431

20. Morcuende J.A., Meyer M.D., Dolan L.A., Weinstein S.L. Long-term outcome after open reduction through an anteromedial approach for congenital dislocation of the hip. J. Bone Joint Surg. Am., 1997, vol. 79, no. 6, pp. 810-817. DOI: 10.2106/00004623-199706000-00002

21. Baki M.E., Baki C., Aydin H., Ari B., Özcan M. Single-stage medial open reduction and Pemberton acetabuloplasty in developmental dysplasia of the hip. J. Pediatr. Orthop. B, 2016, vol. 25, no. 6, pp. 504-508. DOI:10.1097/BPB.0000000000000360

22. Ning B., Yuan Y., Yao J., Zhang S., Sun J. Analyses of outcomes of one-stage operation for treatment of late-diagnosed developmental dislocation of the hip: 864 hips followed for 3.2 to 8.9 years. BMC Musculoskelet. Disord., 2014, vol. 15, pp. 401. DOI: 10.1186/1471-2474-15-401

23. Schoenecker P.L., Dollard P.A., Sheridan J.J., Strecker W.B. Closed reduction of developmental dislocation of the hip in children older than 18 months. J. Pediatr. Orthop., 1995, vol. 15, no. 6, pp. 763-767. DOI: 10.1097/01241398-199511000-00008

24. Malvitz T.A., Weinstein S.L. Closed reduction for congenital dysplasia of the hip. Functional and radiographic results after an average of thirty years. J. Bone Joint Surg. Am., 1994, vol. 76, no. 12, pp. 1777-1792. DOI: 10.2106/00004623-199412000-00004

25. Olney B., Latz K., Ashner M. Treatment of hip dysplasia in older children with a combined one-stage procedure. Clin. Orthop. Relat. Res., 1998, no. 347, pp. 215-223.

26. Berkeley M.E., Dickson J.H., Cain T.E., Donovan M.M. Surgical therapy for congenital dislocation of the hip in patients who are twelve to thirty-six months old. J. Bone Joint Surg. Am., 1984, vol. 66, no. 3, pp. 412-420.

27. Huang S.C., Wang J.H. A comparative study of nonoperative versus operative treatment of developmental dysplasia of the hip in patients of walking age. J. Pediatr. Orthop., 1997, vol. 17, no. 2, pp. 181-188. DOI: 10.1097/00004694-199703000-00009

28. Haidar R.K., Jones R.S., Vergroesen D.A., Evans G.A. Simultaneous open reduction and Salter innominate osteotomy for developmental dysplasia of the hip. J. Bone Joint Surg. Br., 1996, vol. 78, no. 3, pp. 471-476.

29. Mazloumi M., Omidi-Kashani F., Ebrahimzadeh M.H., Makhmalbaf H., Hoseinayee M.M. Combined Femoral and Acetabular Osteotomy in Children of Walking Age for Treatment of DDH; A Five Years Follow-Up Report. Iran. J. Med. Sci., 2015, vol. 40, no. 1, pp. 13-18.

30. Wang T.M., Wu K.W., Shih S.F., Huang S.C., Kuo K.N. Outcomes of Open Reduction for Developmental Dysplasia of the Hip: Does Bilateral Dysplasia Have a Poorer Outcome? J. Bone Joint Surg. Am., 2013, vol. 95, no. 12, pp. 1081-1086. DOI: 10.2106/JBJS.K.01324

31. Teplenky M.P., Oleinikov E.V. Rekonstruktsiia tazobedrennogo sustava u detei shkolnogo vozrasta s vrozhdennym vyvikhom bedra [Reconstruction of the hip in school-age children with congenital hip dislocation]. Genij Ortopedii, 2013, no. 1, pp. 36-39. (in Russian)

32. Teplenky M.P., Oleinikov E.V., Bunov V.S. Khirurgicheskoe lechenie detei s displaziei tazobedrennogo sustava, oslozhnennoi asepticheskim nekrozom golovki bedrennoi kosti [Surgical treatment of children with the hip dysplasia, complicated by aseptic necrosis of the femoral head]. Ortopediia, Travmatologiia i Vosstanovitelnaia Khirurgiia Detskogo Vozrasta, 2019, vol. 7, no. 1, pp. 25-34. (in Russian)

Received: 19.04 .2021

\section{Information about the authors:}

1. Mikhail P. Teplenky, M.D., Ph.D.,

Ilizarov National Medical Research Centre for Traumatology and Orthopedics, Kurgan, Russian Federation, Email: teplenkiymp@mail.ru

2. Evgenii V. Oleinikov, M.D., Ph.D.,

Ilizarov National Medical Research Centre for Traumatology and Orthopedics, Kurgan, Russian Federation,

Email: orto-kgn@mail.ru

3. Vyacheslav S. Bunov, M.D., Ph.D.,

Ilizarov National Medical Research Centre for Traumatology and Orthopedics, Kurgan, Russian Federation, Email: bvsbunov@yandex.ru 